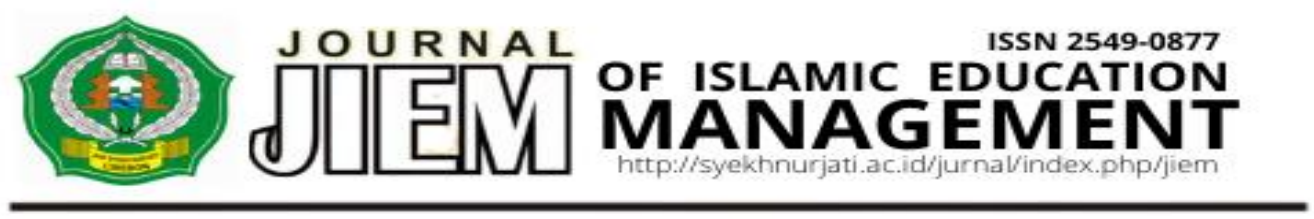

\title{
MANAJEMEN MASJID AGUNG BREBES DALAM DAKWAH ISLAM DI KAMPUNG KAUMAN
}

\author{
Irin Maulana Bahtiar, Mukhlisoh \\ Universitas Muhammadiyah Purwokerto, IAIN Syekh Nurjati Cirebon \\ Email : maulana.irin03@gmail.com, mukhlisoh@gmail.com
}

\begin{abstract}
ABSTRAK
Tujuan dari penelitian ini adalah (1) untuk menjelaskan Sejarah Pengembangan Masjid Raya Brebes, (2) untuk menjelaskan Manajemen dan Konstruksi Masjid Raya Brebes, (3) menjelaskan peran dakwah di bidang agama, pendidikan dan masyarakat. Metode yang digunakan dalam penelitian ini adalah metode historis yang meliputi empat langkah penelitian, yaitu: (1) Heuristik (kumpulan sumber. Dalam penelitian ini sumber diperoleh melalui sumber lisan, sumber tertulis dan objek). (2) Kritik (Verifikasi) adalah penilaian sumber Pada tahap kritik dilakukan kritik eksternal dan internal sehingga fakta sejarah akan diperoleh. Pada kritik eksternal peneliti benar-benar memilih sumber untuk kredibilitas penelitian dan ada kritik internal peneliti menggambarkan fakta sejarah secara terperinci. Pada tahap ini peneliti mulai menafsirkan atau memberi makna, dan (4) Historiografi (penulisan sejarah), yaitu menyusun deskripsi berdasarkan fakta sejarah yang diperoleh. Hasil penelitian ini adalah (1) Masjid Agung Brebes dibangun pada tahun 1836 dengan luas 666m2 yang dibangun oleh Bupati Brebes Raden Ariya Singasari Pranatayuda I, pada akhir masa pemerintahannya. (2) Manajemen Yayasan Masjid Agung Brebes dan Konstruksi bangunan yang dipertahankan setelah melalui renovasi pada tahun 1931/1942 dan 2007/2010, seperti mihrab asli, liwan, drum, kubah dan langit-langit dari hasil renovasi kedua (1931/1942). (3) Peran Dakwah Masjid Agung Brebes di Bidang Agama, Pendidikan dan Masyarakat.
\end{abstract}

Kata kunci: Masjid Raya Brebes, Manajemen, Peran Masjid Dakwah

\begin{abstract}
The aims of the research are (1) to explain the Development History of the Brebes Great Mosque, (2) to explain the Management and Construction of the Brebes Great Mosque, (3) explains the role of Da'wah in the fields of religion, education and society. The method used in this study is a historical method which includes four steps of research, namely: (1) Heuristics (collection of sources. In this study the sources obtained through oral sources, written sources and objects). (2) Criticism (Verification) is assessment of sources At the critics stage external and internal criticisms are carried out so that historical facts will be obtained At external critics the researcher really chooses the sources for the credibility of the
\end{abstract}


research and there is internal criticism the researchers describe historical facts in detail.In this stage the researcher begins to interpret or give meaning, and (4) Historiography (writing history), namely compiling a description based on historical facts obtained.

The results of this study are (1) the Great Mosque of Brebes was built in 1836 with an area of $666 \mathrm{~m} 2$ which was built by the Regent of Brebes Raden Ariya Singasari Pranatayuda I, at the end of his reign. (2) Management of the Brebes Great Mosque Foundation and Construction of buildings that were maintained after going through renovations in 1931/1942 and 2007/2010, such as the original mihrab, liwan, drum, dome and ceiling from the results of the second renovation (1931 / 1942). (3) The Role of Da'wah of the Brebes Great Mosque in the Fields of Religion, Education and Society.

Keywords Brebes Great Mosque, Management of Mosque, Role of Da'wah Mosque

\section{Pendahuluan}

Kedatangan Islam di berbagai daerah di Indonesia tidaklah bersamaan. Kerajaan-kerajaan dan derah-daerah yang didatangi pedagang belum mempunyai situasi politik dan sosial-budaya yang berlainan. Pada waktu kerajaan Sriwijaya mengembangkan kekuasaanya pada sekitar abad ke-7 dan ke-8, Selat Malaka sudah mulai dikunjungi pedagang-pedagang muslim perlayaranya ke negeri-negeri Asia Tenggara dan Asia Timur. Berdsarkan berita Cina zaman Dinasti T'ang, pada abad-abad tersebut diduga masyarakat muslim telah ada, baik di Kanfu (Kanton) maupun daerah Sumatra sendiri. Perkembangan pelayaran dan perdagangan yang bersifat internasional antara negerinegeri di Asia bagian barat dan timur mungkin disebabkan oleh kegiatan kerajaan Islam di bawah Banu Umayyah di bagian barat maupun kerajaan Cina zaman Dinasti T'ang di Asia timur serta kerajaan Sriwijaya di Asia Tenggara. (Poesponegoro. 2008:1).

Masuk dan berkembangnya Islam di Indonesia memberikan pengaruh. Pengaruh tersebut tidak hanya sebatas pada bidang mental spiritual, tetapi juga dalam wujud budaya yang dilakukan oleh masyarakat. Salah satu pengaruh ditandai dengan adanya bangunan masjid. Bangunan masjid merupakan salah satu wujud penampilan budaya Islam. Agama Islam telah memberikan corak tersendiri dalam perkembangan seni dan budaya Indonesia pada masa madya, terutama dalam seni bangunan Islam telah berhasil memadukan bangunan seni tradisional dengan budaya Islam sehingga menghasilkan bentuk seni yang berbeda dari negeri Islam lainya (Daliman, 2012: 60-62) .

Bahkan bukan hanya seni dan budaya, begitu juga dengan masjid sebagai bentuk penampilan budaya Islam, letak bangunan tersebut biasanya di sebelah barat alun-alun dan tidak terpisahkan dari komposisi tata kota inti di mana terdapat keraton. Dengan adanya masjid yang letaknya di sebelah barat alun-alun pusat kota itu, tidak berarti bahwa dalam sebuah kota hanya didirikan sebuah masjid. Berdasarkan data sejarah, ternyata dalam sebuah kota pusat kerajaan terdapat sebuah masjid. Kecuali bangunan yang disebut masjid di beberapa bagian kota terdapat pula surau, tajug, langgar, atau meunasah (Aceh) yang juga dipakai sebagai tempat peribadatan umum. Pendirian masjid, surau, tajug lebih dari satu dalam suatu masyarakat sudah tentu disesuaikan 
dengan kebutuhan masyarakat yang makin lama makin berkembang.

Dilihat dari Arsitektur, Masjid kuno di Indonesia menujukan kekhasan yang membedakanya dengan arsitektur masjid di negeri Islam lainya. Mengenai asal pengaruh yang terdapat pada masjid yang mempunyai corak atau gaya Indonesia itu ada dua pendapat. Pertama, pendapat yang menyatakan adanya pengaruh gaya masjid dari India, dari daerah Malabar, seperti dikemukakan oleh H.J de Graaf. Kedua, pendapat bahwa gaya masjid dengan atap bertingkat berasal dari Indonesia sendiri, yaitu merupakan tradisi seni bangunan candi yang telah dikenal pada zaman Indonesia-Hindu. Gaya khas masjid kuno Indonesia itu sesuai dengan gaya bangunan keraton dan bagian-bagian lainya. (Poesponegoro. 2008:321-323).

Ditinjau lebih spesifik dari beberapa gaya bangunan masjid, karakter penduduk dan daerah di masing-masing wilayah yang ada di Indonesia, khususnya daerah Brebes, secara geografis, Kabupaten Brebes berbatasan dengan Kabupaten Tegal (timur), bekas Krasidenan Banyumas (selatan), bekas Karesidenan Cirebon (barat), dan laut jawa (utara). Pada abad ke-17, Wilayah ini merupakan bagian dari Kerajaan Mataram yang menyebut daerah ini dengan nama daerah Pesisir kulon. Penduduk Kabupaten Brebes mempunyai dua Bahasa yang digunakan dalam keseharianya, yaitu bahasa jawa di bagian utara dan timur, serta berbahasa Sunda di bagian barat dan selatan. Tetapi diluar keluarga, mereka bisa menggunakan Bahasa Indonesia.

Masyarakat Brebes tidak hanya terdiri dari dua Etnis Jawa dan Sunda saja, melainkan multietnis yakni juga terdiri dari orang Manado, Ambon, Indo-Belanda, Arab dan Tionghoa, yang dominan tinggal didaerah perkotaan.

Kebanyakan penduduk Kabupaten Brebes beragama Islam. Agama ini besar pengaruhnya bagi kehidupan masyarakat setempat, baik dalam segi budaya maupun adat istiadat. Agama lainya yang dianut sebagian kecil penduduk adalah Kristen dan Buddha. Kerukunan beragama di antara penduduk Kabupaten Brebes terjalin dengan baik. (Aman.2015:34-35)

\section{Pembahasan}

\section{A. Sejarah Masjid Agung Brebes}

Pada tahun 1670 daerah Brebes belum menjadi daerah kabupaten yang berdiri sendiri. Oleh penguasa kerajaan Mataram Amangkurat I, daerah tersebut masih digabungkan denagn daerah Losari dan Tegal. Pada tanggal 3 September 1677 Wirasuta mendapat surat pengangkatan menjadi Bupati Brebes yang pertama oleh Sunan Amangkurat I setelah Brebes dipisahkan dari daerah Losari dan Tegal. (Suduri. 2008)

Pada tanggal 1 Juli 1809 Kyai Sura Patih dari Krawang diangkat menjadi Bupati Brebes. Sebagai Bupati yang kelima dengan gelar Raden Adipati Ariya Singasari Pranatayuda I Surat pengangkatan ditanda tangani. Raden Adipati Ariya Singasari Pranatayuda I dikenal pula sebagai Khalifatullah Sayidin Panetep Panatagama atau dipanggil Kyai Sura yang memerintah pada tahun 18091836. Raden Adipati Ariya Singasari Pranatayuda I sangat aktif menyiarkan Agama Islam dan pada akhir pemerintahan sebagai pemimpin, Raden Adipat Ariya Singasari Pranatayuda I membangun masjid pada tahun 1836 yang kemudian dikenal dengan Masjid Agung yang masih baru. Tanah tempat membangun masjid adalah tanah wakaf dan atas perintah dan kekuasan Bupati. Sebagai pengganti Bupati Brebes Raden Adipati Ariya Singasari Pranatayuda I adalah Ariya Singosari Panatayuda II sampai pada Ariya Singosari Panatayuda III Setelah itu tidak ada lagi Bupati Brebes dari keturunan Kerawang. (Suduri. 2008)

Sejarah Masjid Agung Brebes tidak lepas dengan sejarah Bedug kembar yang pernah ada didalam masjid tersebut menurut riwayat yang dapat dipercaya 
bedug tersebut dari kayu sawo besar yang diambil dari suatu desa ditepi pantai. Kayu sawo tersebut berjajar dua sehingga desa itu dinamakan Sawojajar sekarang bedug tersebut tinggal satu sebab satu lainya diserahkan untuk masjid di Kecamatan Jatibarang. Pada zaman Pemerintah Hindia Belanda pengurusan dan pemeliharaan Masjid Agung Brebes diurus langsung oleh kyai penghoeloe landrat sebagai pemimpin agama tertinggi di daerah kabupaten secara formal. Peranan Masjid Agung Brebes dalam fungsinya sebagai tempat ibadah dan sarana membentukan akhlaq warga Brebes kota dan sekitarnya sangat besar dari masa ke masa. (Suduri. 2018)

Masjid Agung Brebes terdapat di Kelurahan Brebes, Kecamatan Brebes, Kabupaten Brebes yang berada di Jl.Ustad Abas No.7, Kauman, Brebes, Kec.Brebes. Kabupaten Brebes. Di sebelah selatan Masjid Agung Brebes terdapat Bangunan Pendopo Brebes, di Sebelah Utara terdapat jalan pantura dan berdekatan dengan bangunan Klenteng Ho Tek Bio, di sebelah Timur terdapat Alun-alun kota berdampingan dengan Lapas dan juga Pasar Tradisional, di sebelah barat terdapat kampong kauman yang berdekatan dengan Sungai Pemali. (Suduri. 2018)

\section{B. Pengertian dan Peran Dakwah}

Ditinjau dari Etimologi atau Bahasa, kata dakwah berasal dari Bahasa Arab, yaitu $d a$ 'a-yad'u-da'watan, artinya mengajak, menyeru, memanggil. Sedangkan secara terminologi definisi mengenai dakwah pada makna hakikinya sama. Menurut Toha yahya dakwah bertujuan mengajak manusia dengan cara bijaksana kepada jalan yang benar sesuai dengan perintah Tuhan, untuk keselamatan dan kebahagiaan mereka di dunia dan akhirat. Sedangkan menurut $M$. Natsir. Dakwah adalah usaha-usaha menyerukan dan menyampaikan kepada perorangan manusia dan seluruh umat manusia konsepsi Islam tentang pandangan dan tujuan hidup manusia di dunia ini, dan meliputi al-amar bi alma'aruf an-nahyu an al-munkar dengan berbagai macam cara dan media yang di perbolehkan ahlak dan membimbing pengalamanya dalam peri-kehidupan bermasyarakat dan perikehidupan bernegara. Sebagimana Peran dakwah mengemban unutk memulihkan keseimbangan di era globalisasi yang mengarahkan pembebasan, persaingan pun tampak dinamika budaya yang lain, sekaligus meletakan pola dakwah dalam berbagai perspektif, termasuk perspektif kultural. Dakwah pada wilayah ini berfungsi sebagai Agen of social change. Samsul, (munir.2009:224).

Sebagaimana dijelaskan diatas pengurus Yayasan Masjid Agung Brebes sudah melakukan kegiatan dakwah secara berjenjang dari tahun ke tahun menciptakan kultural di Bidang dakwah keagamaan, dakwah di bidang pendidikan dan dakwah di bidang kemasyarakatan. Beberapa agenda baik harian, mingguan, bulanan dan tahunan.

\section{a. Peran di Bidang Keagamaan}

1. Peringatan Nuzulul Al-Quran Memperingati Turunya wahyu sampai pada titik menjadi kitab al-Quran di bulan Ramadhan. Sejarah Islam mencatat, jejak risalah Nabi Muhammad SAW, sifat dan kaitanya dengan ajaran nabi terdahulu, Allah menciptakan umat manusia dengan maksud dan tujuan untuk menghambakan diri kepada-Nya. Meski ia tidak memerlukan seseorang agar menyembah karena tidak akan menambah arti kekuasaan-Nya. Tata cara penyembahan tidak serta merta diserahkan pada individu, akan tetapi secara eksplisit diterangkan oleh para nabi dan rasul-Nya. Semua nabi dan rasul menerima tugas dari Allah yang sama, inti risalah tetap sama, hannya beberapa penjelasan praktis yang mengalami perubahan. (Al-Azmi, 2005:43). 
Adapun mekanisme turunya wahyu, tidak selalu sama, akan tetapi beraneka ragam Rasulullah cara menerimanya, menurut M. AL A'zami diantara peristiwa tersebut : Pertama, dengan bunyi lonceng, ketika sahabat Al Harith bin Hisham bertanya Wahai Rasulullah bagaimana wahyu itu sampai kepadamu? Beliau menjawab kadangkadang seperti bunyi lonceng, dan itu sesuatu yang paling dahsyat yang sampai pada saya, kemudian lenyap dan saya dapat mengulangi apa yang dikatakan. Kadang-kadang malaikat hardir dalam jelmaan manusia dan berkata kepadaku dan saya dapat memahami apa yang dikatakan. Aisya menuturkan, sungguh aku pernah melihat Nabi saat wahyu turun kepadanya dimana pada hari itu beliau merasa kedinginan sebelum wahyu berhenti dan dahinya penuh keringat. Kedua, Ya'la pernah sesekali bercerita pada Umar tentang keinginan melihat Nabi Muhammad SAW menerima wahyu, pada kesempatan lain Umar memanggil dan ia menyaksikan Nabi Muhammad wajahnya kemerah-merahan, bernafas sambal ngosngosan. Lalu tampak sembuh dari gejala itu. Ketiga, Zaid bin Tsabit menjelaskan, Ibnu Um-Maktum mendatangi Nabi Muhammad saat beliau mendektekan ayat ini : la yastawil qaiduna minal mukminin, tak akan sama diantara orang-orang beriman yang duduk(tanpa kerja). Saat itu medan perang (jihad). Dia seorang yang buta. Kemudia Allah memwahyukan (ayat peringatan) kepada Rasulullah saat kakinya berada diatas kakiku, begitu beratnya dan saya khawatir kakiku terasa akan putus.

Implikasinya dari sejarah turunya wahyu al-Quran akan terlihat jejak risalah Nabi SAW, sifat dan kaitanya dengan ajaran para nabi terdahulu. Namun secara eksplisit dijelaskan oleh para Nabi dan Rasul-Nya. Melihat bahwa semua rasul menerima tugas dari Pencipta yang sama, inti risalah tetap saja sama, hanya beberapa penjelasan praktis yang mengalami perubahan.. (Yusron, 2017: Vol.16:hlm 42-43).

Peringatan nuzulul al-Quran dilakukan tepat pada 17 Ramadhan dengan melakukan dakwah ceramah peristiwa nuzulul al-Quran di Masjid Agung Brebes dan mengaji dari pertengahan juz'ama sampai dengan selesai. Dipimpin oleh KH. Ahmad Zaeruki. Dilanjutkan malam Lailatul Qodar (Wawancara dengan Mas Rifki pengurus Masjid Agung Brebes 1007-2019).

2. Tadarus al-Quran

NabiMuhammad menjelaskan kandungan Al-Quran, tidak hanya sebatas membaca Al-Quran yang ingin diajarkan Nabi kepada para sahabat, tetapi juga maknanya. Menurut Yusuf al-Qardhawi, tugas penting yang diperintahkan untuk Nabi terhadap Al-Quran adalah mengajarkan kitab dan hikmah. Hal itu di tegaskan dalam empat ayat Al-Quran. "Mengerjakan" disini jelas bukan dalam arti "menghafal". Ia di kaitkan dengan ativitas "membaca". Allah berfirman : yang membacakan ayat-ayat Allah kepad mereka, membersihkan jiwa mereka, dan mengerjakan Al-Kitab dan hikmah kepada mereka. "mengerjakan" memiliki arti yang lebih khusus daripada "membaca".

Kegiatan belajar dan mengerjakan Al-Quran inilah yang dalam beberapa hadis dengan "Tadarus". Dalam Shahih Muslim, Abu Hurairah meriwayatkan bahwa Nabi saw. Bersabda, "Bila kelompok orang berkumpul di masjid dan membaca Al-Quran, saling bertadarus, pasti mereka diberi ketenangan, diliputi rahmat dan kasih sayang, dikelilingi para malaikat. Dan, Allah akan menyebut mereka kepada semua yang ada di sisiNya.

Tadarus disini maksudnya berusaha mengenali susunan Al-Quran, memahami dan menangkap maknanya, menyibak hukum dan nilai yang terkandung didalamnya. Syekh Muhammad al-Ghazali mengatakan, tadarus Al-Quran adalah membaca, memahami, merenungkan, dan 
menguatkan pemahaman tentang sunatullah dalam diri kita dan alam semesta, berusaja mengetahui pesan, hukum, ganjaran dan hukuman, janji dan ancaman, serta segala hal yang menyangkut kebutuhan kaum muslim. (Majdi.2011: 109-111)

Kegiatan Tadarus Al-Quran di Masjid Agung Brebes sudah ada sejak 1950 disamping hanya untuk shalat jam'ah, setiap bulan Ramadhan setiap ba'da Ashar tadarus Al-Quran yang dibaca oleh KH. Munawir dari Ketanggungan yang asli Slatri Lor dipandu oleh Ibrahim bin Munaseh Kauman Brebes. Malam hidup dengan sholet tarawih dan sholat witir juga diimami KH. Munawir. Tadarus Al-Quran ba'da ashar dan imam tarawih hanya sampai tanggal 25 Ramadhan. Hal ini sudah menjadi kultur Masjid Agung Brebes sampai saat ini.

\section{Pengajian Kitab Ihya' ulum al-Din} Kitab Ihya' ulum al-Din merupakan karya cendakiawan muslim sufi Abdul Hamid Muhammad ibn Muhammad al-Ghazali yang lahir pada tahun $450 \mathrm{H} / 1085 \mathrm{M}$ di Thus (suatu kota kecil di Khurasan, Persia, Iran). Karya AlGhazali Ihya' ulum al-Din membahas tentang menghidupkan Ilmu-ilmu agama dimana beliau sangat mendukung dan menjadikan sufisme sebagai way of life (jalan hidup) seseorang muslim. AlGhazali dalam kitab Ihya' ulum al-Din banyak mengekplorasi maqamat dan ahwal seperti telah diletakan fondasinya oleh para sufi sebelumnya, ia berbicara tentang taubat, keutamaan riyadah, zuhud, tawakkal dan ridha. (Arrafie \& Syofrianisda 2017:Vol.25hlm71-75).

Pengajian kitab Ihya' ulum al-Din di Masjid Agung Brebes dilaksanakan setiap rabu sore ba'da ashar satu minggu sekali. Di isi oleh KH. Subkhan Makmun pengasuh pondok pesantren Luwungragi kecamatan wanasari kabupaen Brebes, metode yang dipakai untuk menjelaskan kitab Ihya' ulum al-Din kepada peserta pengajian menggunakan ceramah sercara bertahap agar berkesinambungan. Peserta pengajian baik dari wanasari, pasarbatang, kampung kauman yang dekat dengan Masjid Agung Brebes. Serta para pengunjung dari berbagai daerah dan kecamatan lain hanya saja tidak langsung ke liwan masjid. (Wawancara dengan Mas Rifki pengurus Masjid Agung Brebes 10-07-2019).

\section{Pengajian Kitab Riyaadhush Shaalihiin \\ Kitab Riyaadhush Shaalihiin} merupakan kitab karya dari cendakiawan muslim sufi Yahya bin Syaraf bin Murry bin Hasan bin Husain bin Muhammad Ju'mah bin Hizam atau lebih dikenal Imam an-Nawawi. Imam an-Nawawi dilahirkan pada pertengahan bulan Muharram, tahun $613 \mathrm{H}$ di Nawa, sebuah daerah dari bumi Hauran, bagian wilayah Damaskus. Imam an-Nawawi dalam bidang ilmu hadits berhasil menulis kitab yang salah satunya adalah kitab Riyaadhush Shaalihiin. (menuju jalan yang benar). (AlHilal.2005:4-8).

Pengajian Kitab Riyaadhush Shaalihiin masih eksis sampai sekarang di Masjid Agung Brebes dilaksanakan setiap sabtu sore ba'da ashar, di isi oleh $\mathrm{KH}$. Ahmad Zaeruki. Metode penyampaian yang digunakan adalah ceramah dan mencatat setiap hadist yang dibacakan oleh KH. Ahmad Zaeruki. Memuat pengetahuan kehidupan untuk menuju kejalan yang benar. Peserta pengajian kitab Riyaadhush Shaalihiin sekitar 20-30 orang apabila baru memulai kembali pengajian kitab Riyaadhush Shaalihiin karena adanya acara hari raya idul fitri. Selanjutnya setiap rabu ba'da ashar pengajian kitab Riyaadhush Shaalihiin peserta pada kondisi setabil antara 40-50 orang terkadang juga bisa lebih dari 50 orang peserta, yang mengikuti pengajian ini ratarata lokal yang berdekatan dengan Masjid Agung Brebes. (Wawancara dengan Mas Rifki pengurus Masjid Agung Brebes 1007-2019). 
5. Pengajian Kitab Irsyadul'Ibad Kitab Irsyadul'Ibad terdiri dari dua jilid, jilid pertama mencakup bab iman, murtad, ilmu, wudhu, mandi, sembahyang jum'at, niyanah (merintihrintih karena kematian), zakat, puasa, haji, fadhilah al-quran, dzikir untuk pagi dan sore, bacaan ketika akan tidur dan bangun tidur. Sedangkan jilid kedua mencakup bab fadhilah membaca sholawat Nabi s.a.w, syirik yang kecil (samar) yaitu Riyaa', ujub dan sombong, marah, fadhilah mema'afkan dan menahan amarah, ghibah (menyebutkan kejelekan orang), naminah (memfitnah/mengadu domba), dusta, amar ma'ruf dan nahi munkar, kasab, mencela pegawai bea cukai, dzalim (aniaya), wasiat, nikah, boikot-memboikot, durhaka terhadap bapa ibu, pembunuhan, jihad, perdukunan, tebak-tebakan, sihir (tenun) ilmu nujum dan mencari nasib dengan burung, zina, liwath (pelacur laki dengan laki) minum khamr, sumpah palsu, saksi palsu, tobat.

Pengajian Kitab Irsyadul'Ibad dilaksanakan pada setiap malam senin sehabis ba'da isya yang diisi oleh $\mathrm{KH}$. Jafar Atoya, metode yang disampaikan tidak jauh berbeda dengan pengajian Kitab Riyaadhush Shaalihiin dan Kitab Ihya' ulum al-Din. (Wawancara dengan Mas Rifki pengurus Masjid Agung Brebes 1007-2019)

\section{Kuliah Dhuha}

Kuliah Dhuha Dilaksana setiap hari minggu yang digelar oleh pengurus masjid terutama di bidang dakwah dan pendidikan seperti pak H.Syamsudin, Deni Irmawan, SH.I.,M.Pd.I , H. Fathoni, Lc. Dan pak Nur Kholis, S.Pd dari bidang perpustakaan (pengurus yayasan periode 2015-2020). (Wawancara dengan Mas Rifki pengurus Masjid Agung Brebes 1007-2019).

Para peserta diisi dari siswa/siswi SMP/SMA/MA/SMK Negeri maupun di Kabupaten Brebes. Kuliah Dhuha ini dimulai sejak 1985. Dilaksanakan mulai jam 08.00-09.30. (wawancara dengan Mas
Rifki sebagai pengurus Masjid Agung Brebes). Ditahun 2005 dipimpin oleh Alm.Suduri mantan guru SMEA (SMK) 1 Brebes, Deni Irkhami, S.Ps.I guru MTS Model dan sekretaris Drs.Muh.Firdan. setiap hari minggu kuliah dhuha diadakan kurang dari 400-500 siswa hadir untuk mengikuti kuliah dhuha. Jumlah perserta hingga kini masih stabil. Para pembicara dalam kuliah dhuha mulai dari para ulama setempat, cendakiawan, guru agama dan pejabat pemerintahan Brebes. (Suduri 2008)

\section{Khotmil Quran}

Khotmil quran adalah publikasi atas prestasi didik selama menempuh pembelajaran, dan di ikbar atau diumumkan dan dites di hadapan wali santri, dengan menimbang bacaanya, tajwid, tes doa-doa harian dan termasuk bacaan hafalan aquranya. Khotmil quran di Masjid Agung Brebes diakan setiap satu bulan sekali diambil pada hari senin pon (tanggal jawa) sehabis ba'da asyhar dipimpin oleh Ustad Zaenal Mustaqin. Pada prakteknya Ustad Zaenal Mustaqim membaca al-quran berbarengan dengan peserta khotmil quran, apabila ada kesalahan membaca dari Ustad Zaenal Mustaqim maka tugas peserta khotmil quran yang membenarkan dan mengulagi bacaan yang salah tersebut. Hal ini bertujuan untuk tes peserta akan sejauh mana mereka hafal dan memahami bacaan al-quran (wawancara dengan Mas Dani sebagai pengurus PRIMA).

\section{b. Peran di Bidang Pendidikan}

Secara etimologis pendidikan diterjemahkan ke dalam bahasa arab "Tarbiyah" dengan kata kerjanya "Robba" yang berarti mengasuh, mendidik, memelihara. Menurut pendapat Ki Hajar Dewantara pendidikan adalah tuntunan di dalam hidup tumbuhnya anak-anak, maksudnya pendidikan adalah menuntun segala kekuatan kodrat yang ada pada anak-anak itu, agar mereka sebagai manusia dan asebagi anggota masyarakat 
dapat mencapai keselamtan dan kebahagiaan yang setinggi-tingginya. (Syaikhu.2011.Vol:2 hlm 120).

Di Masjid Agung Brebes terdapat pendidikan non formal seperti :

1. Perpustakaan Masjid Agung
Brebes
Strategi dan pendekatan pembinaan umat bukan hanya sebatas di peribadatan tetapi juga diperkuat dan diperkaya melalui pendekatan lain yang mampu mendorong dan memotivasi para jama'ah agar lebih aktif mencari dan mempelajari Islam secara terbimbing melalui budaya baca (iqra). Bila strategi dan pendekatan dakwah sudah tertumpu pada budaya baca dan jama'ah secara aktif mencari dan mempelajari Islam secara mandiri dan terbimbing, disinilah perpustakaan masjid akan dibutuhkan dan berperan penting dalam membangun dan mencerdask an umat. (Ahmad yani.2007: 319-320).

Perpustakaan Masjid Agung Brebes dibangun dan berlokasi di masjid yang dimaksudkan untuk digunakan oleh masyarakat sekitar maupun jama'ah. Perpustakaan Masjid Agung Brebes ini dipimpin oleh ketua bidang perpustakaan H. Nur Kholis, S.Pd membawa anggota Muhammad Habib dan Fitriani Nafiatunisa, S.P.d. Terdapat buku-buku tentang Islam, pengetahuan umum dan buku anak-anak. Diakui oleh pihak pengurus masjid bahwa fasilitas buku masih kurang dan masih banyak yang harus dipenuhi agar perpustakaan menjadi maksimal dalam pelayananya. Perpustakaan Masjid Agung Brebes ini dibuku setiap hari pada pukul 13.00 WIB s/d 17.00 WIB. Masyarakat atau para jama'ah Masjid Agung Brebes diperbolehkan meminjam buku, pihak pengurus membuatkan kartu pinjaman buku apabila masyarakat atau para jama'ah Masjid Agung Brebes ingin meminjam jaminanya adalah Kartu Tanda Penduduk (KTP). (Wawancara dengan Mas Rifki pengurus Masjid Agung Brebes 10-072019).

2. Taman Pendidikan Al-Quran.

Kegiatan taman pendidikan alquran dilakukan diluar Masjid Agung Brebes dikarenakan status Masjid bukan hanya konsumsi masyarkat seikitar tetapi sudah daerah bahkan nasional. Untuk taman pendidikan al-quran ditempat salah satu pengurus masjid yaitu Bapak Otong Saputra, S.sos. kegiatan ini setiap hari dibuka pada jam 18.30 atau sehabis ba'da magrib. Masyarkat kauman diberikan pendidikan al-quran mulai dari anak-anak tingkat taman kanak-kanak hingga sekolah menengah dasar. Membaca Iqro, Juz'ama dan al-quran biasanya setelah membaca lalu dilakukan tes hafalan dari mereka yang sudah membaca baik iqro, juz'ama dan al-quran. (wawancara dengan Mas Rifki sebagai pengurus Masjid Agung)

\section{c. Peran di Bidang Kemasyarakatan}

1. Persatuan Remaja Islam Masjid Agung (PRIMA) Brebes

Merupakan sebuah organisasi yang berdiri di bawah naungan Yayasan Masjid Agung Brebes, serta merupakan organisasi sosial yang bergerak pada bidang keagamaan dan masyarakat yang beranggotakan pelajar (SMP dan SMA). PRIMA ini dibentuk untuk menjaring remaja-remaja dari kampong kauman agar aktif beroganisasi di masjid Agung Brebes dengan waktu per periode pengurus Prima selama dua tahun sekali dalam pemilihan pengurus Prima. Banyak kegiatan yang dilakukan Prima yang memfasilitasi kegiatan-kegiatan masjid Agung Brebes.

2. Qurban

Qurban berasal dari bahasa Arab, "Qurban", yang berarti dekat. Didalam ajaran Islam, qurban disebut juga aludhhiyyah dan adh- dhahiyyah yang berarti binatang sembelihan, seperti unta, sapi atau kerbau dan kambing yang 
disembelih pada hari raya idhul adha dan hari- hari tasyriq sebagai bentuk taqarrub atau mendekatkan diri kepada Allah. Nabi Muhammad saw dan para sahabat beliau senantiasa berqurban, bahkan Nabi bersabda bahwa qurban merupaka sunah kaum muslimin. Oleh karena itu, umat Islam bersepakat bahwa berqurban itu disyariatkan, sebagaimana keterangan beberapa ulama. Namun terdapat perbedaan pendapat ulama tentang hukumnya, ada yang mengatakan wajib bagi yang memiliki kelapangan rezeki, ada pula yang mengatakan Sunnah mu'akadah. Tidak semua hewan bisa dijadikan sembelihan qurban. Sebab, ini adalah ibadah yang sudah memiliki petunjuk bakunya dalam syariat yag tidak boleh diubah, baik ditambahmaupun dikurang. (Mulyana.2016:Vol.14:hlm 109-112).

Di Masjid Agung Brebes setiap tahunya wajib mengadakan shalat idul adha, pemotongan hewan qurban dan mendistribusikan hewan qurban kepada masyarakat setempat. Sebelum pemotongan hewan qurban biasanya menyiapkan shoft-sohft untuk masyarakat sholat idul adha dari depan halaman masjid sampai di taman alun-alun Brebes. Dari tahun 2016 hewan qurban seperti sapi,kerbau dan kambing/domba, mendistibusikan daging qurban hampir sama dengan zakat yang menjadi perbedaan adalah lingkupnya lebih terbatas untuk mendistibusikan daging qurban. (Wawancara dengan Mas Dani sebagai pengurus PRIMA).

\section{Zakat}

Secara literal, Zakat berarti tambah (al-ziyadah), tumbuh, subur, dan berkembang (al-nama). sedangkan secara harfiah, zakat berarti bersih/suci (althaharah), berkah (al-barakah), rapi, patut dan damai atau (al-shalah). Dalam terminology para ulama syariah/fikih, zakat diartikan sebagai nama/literature bagi sesuatu harta-kekayaan yang dikeluarkan oleh seseorang dari hak Allah untuk disalurkan kepada kaum fuqara atau, zakat dalam perspektif syarak digunakan untuk menyebutkan nilai/harga yang ditentukan dari harta yang Allah fardukan (Wajibkan) untuk digunakan para mustahiq zakat. Setiap malam Idul Fitri Masjid Agung Brebes mengumpulkan zakat fitri, mendata dan mendistribusikan zakat kepada yang berhak mendapatkan zakat tersebut, dalam menyebarkan zakat di beberapa titik di kampung kauman pertama di RW 12 disekitar Masjid, kedua RW 11 di bagian Kali Pemali, Ketiga, RW 10 di Kampung Kauman, Keempat, RW di Daerah Kleben. Sebelum hari H sekitar 1 atau 2 hari, panitia menyiapkan dan membagikan Kupon kepada masyarakat yang berhak menerima zakat dikarenakan untuk menghindari duplikat kupon penerimaan zakat. (Wawancara dengan Mas Dani sebagai pengurus PRIMA pada tanggal 24-07-2019).

4. Ta'jil

Ta'jil merupakan hidangan pembuka dibulan Ramadhan, setiap bulan Ramadhan Masjid Agung Brebes menyediakan ta'jil untuk masyarakat dan jama'ah pengunjung Masjid Agung Brebes yang berbuka di Masjid Agung Brebes. Pengurus Masjid dibantu PRIMA Brebes menyediakan ta'jil mulai dari jajanan tradisional, minuman, dan makanan berat. Dihidangkan secara gratis. Biasanya para jama'ah diarahkan oleh prima untuk menempati tempat berbuka dibagian tengah masjid yang sudah disediakan meja dan ta'jil. Berbuka bareng dengan para pengurus Masjid Agung Brebes. Disamping itu juga ta'jil ini tidak hanya dibagikan kepada pengunjung jama'ah masjid saja, tetapi juga dibagikan kemasyarakat kampung kauman dan sekitar masjid seperti dialun-alun Brebes. (Wawancara dengan Mas Dani sebagai pengurus PRIMA)

\section{Bedug Takbir}

Bedug merupakan penanda awal, sebelum berkumandangnya Adzan, yang mengajak Umat Muslim untuk 
menunaikan Ibadah Shalat. Berbeda dengan bedug takbir, setap tahun tepatnya menjelang 1 syawal atau menjelang Idulfitri. Masjid Agung Brebes mengadakan festival bedug takbir untujk menyambut Idulfitri dan mempererat Ukhuwah Islamiyah masyarkat kampung kauman pada khususnya dan masyarkat Brebes pada umumnya. Biasanya pengurus Masjid Agung Brebes mengundang seluruh perwakilan Masjid se-Kabupaten Brebes untuk memeriahkan bedug takbir ini. (Wawancara dengan Mas Rifki sebagai pengurus Masjid Agung Brebes).

\section{Kesimpulan}

Masjid Agung sebelum terkenal menjadi Masjid Agung Brebes, Masjid yang dibangun oleh Raden Adipati Ariya Singasari Pranatayuda I dengan luas tanah $666 \mathrm{~m}^{2}$ dengan kontruksi bangunan jawa yang berbentuk joglo dan limas. Masjid Agung Brebes mengalami beberapa renovasi pada tahun 1931-1940 akibat selalu terkena banjir kali pemali dan dibangun tanggul serta diperluas menjadi $2162 \mathrm{~m}^{2}$ hingga sekarang dan ditinggikan pondasi satu meter. Pada perkembanganya Masjid Agung Brebes yng pada renovasi kedua masih tradisional pada kontruksi bangunanya yang bermuatan lokal dan jawa serta sering terbeludaknya jama'ah dibisa menampung lebih dari 2500 jamaah, maka pada renovasi terakhir pada tahun 2007 di rehab. Pada bangunan utama masjid dipertahankan keaslianya hanya pada bagian tengah sampai kedepan dibedah dan diperluas bangunanya dengan model kontruksi masjid Persia. Selesai pada tahun 2010 dan di resmikan oleh Bupati Brebes Bambang Kusuma, Sos. Kini Masjid Agung Brebes bisa menampung lebih dari 3500 jamaah serta bagian utama masjid sudah menjadi cagar budaya sebab masih dipertahankanya bangunan dan arsitektur aslinya. Kepengurusan Yayasan Masjid Agung Brebes yang bersifat seumur hidup dan ada beberapa kriteria apabila tidak menjabat lagi menjadi pengurusan yayasan masjid agung Brebes mulai dari wafat dan mengundurkan diri. Beberapa kontruksi yang masih dipertahankan dari renovasi kedua pada tahun 1931/1942 mulai dari mihrab,mimbar,kubah,joglo dan atap langit-langit masjid dibagian utama masjid.

\section{Daftar Pustaka}

Abdullah, Mulyana. Qurban : Wujud Kedekatan Seorang Hamba dengan Tuhanya. 2016. Vol.14 hlm 110-112

Al-Hilali. Majdi. 2011. Agar AlQuran Menjadi Teman. Jakarta : Penerbit Zaman

Aman. 2015. Revolusi Sosial di Brebes. Yogyakarta: Penerbit Ombak.

Arianto NT. Kajian Etnografi. Disampaikan dalam pelatih Model penelitian Sosial bagi Guru-guru SMA. Selasa 21 juni 2011, di Departemen Antropol FISIP Unair. 2011:1-10

Arrafie\&Syofiandra. Pengaruh Tasawuf Al-Ghazali dalam Islam dan Kristen. 2017.Vol 25 hlm71-75

Atyanto \& Dwindi. Ruang Sakral dan Profan dalam Arsitektur Masjid Agung Demak, Jawa Tengah. Mei 2018:Vol.1 hlm.19

Daliman. A. 2012. Islamisasi dan Perkembangan KerajaanKerajaan Islam di Indonesia. Yogyakarta: Ombak.

Fikriarini, Aulia. Masjid: Bentuk Manifestasi dan Kebudayaan. Januari 2009 : Vol. 11 hlm 7-8.

Ghofut, Abdul. Perspektif Historis Arkeologis Tentang Keragaman Bentuk Masjid Tua di Nusantara. Juni 2005 : Vol .12 hlm 76 
Hadi Waluyo,E. 2013. Alkulturasi Budaya China pada Arsitektur Masjid Kuno di Jawa Tengah

Huda, Dimyati. Pendekatan Antropologis dalam Studi Islam. 2016. Vol.4 hlm142-143

Juliadi. 2007. Masjid Agung Banten (nafas Sejarah dan Budaya).

Yogyakarta:Ombak.

Kuntowijoyo. 2013. Pengantar Ilmu Sejarah. Yogyakarta : Penerbit Tiara Wacana.

Kurniawan S. Masjid dalam lintasan sejarah umat islam. J Islam Stud. 2014;4(2):169-184.

Makhmud Syafei'i. MA. Masjid dalam Prespektif Sejarah dan Hukum Islam. J Islam Stud. 2017;91:399404.

Masduki.Yusron. Sejarah Turunya AlQuran penuh Fenomenal (Muatan Nilai-nilai Psikologi dalam Pendidikan). Juni 2017 : Vol.16 hlm 42-43.

Mohammad. Ayub. 1996. Manajemen Masjid (Petunjuk Praktis Bagi Para Pengurus.). Jakarta: Gema Insani. Munir Amin. Samsul. 2009. Ilmu Dakwah. Jakarta: Penerbit Amzah.

Pahlevi dkk. Meningkatkan Fungsi Masjid Melalui Reformasi Administrasi. 2013. Vol.2 hlm305

Poesponegoro, Marwati Djoened.2008. Sejarah Nasional Indonesia. Jakarta: Balai Pustaka.

Priyadi, Sugeng. 2009. Sejarah Mentalitas Brebes. Yogyakarta: Penerbit Ombak.
Priyadi, Sugeng. 2011. Metode Penelitian Sejarah. Yogyakarta: Pustaka Pelajar.

riyadi, Sugeng. 2013. Dasar-Dasar Ilmu Sejarah.Yogyakarta:

Pustaka Pelajar.

Priyadi, Sugeng. 2015.Historiografi Indonesia. Yogyakarta: Penerbit Ombak

Rachmat\&Anjar. Karakteristik Arsitektur Menara
Masjid Sebagai
Simbol Islam dari Masa ke Masa. 2 Agustus 2013. Vol.10:hlm 12.

Suduri.2008. Sejarah Masjid Agung Brebes. (Key Informan)

Sugiyono. 2017. Metode Penelitian Kualitatif. Bandung: Penerbit Alfabeta.

Suma, Amin. Zakat, Infak dan Sedekah : Modal dan Model Ideal

Pembangunan Ekonomidan Keuangan Moden. Juli 2013. Vol.12 hlm 224-226.

Suryadi, Budi. 2012. Pengantar Antropologi. Yogyakarta. Pencetak Nusa Media

Syaikhu, Ach. Sejarah Pendidikan Islam. September 2011. Vol.2 hlm120

Yani. Ahmad. 2007. Panduan Pengelolaan Masjid. Jakarta: Pustaka Intermasa.

Yusron. Sejarah Turunya Al-Quran Penuh Fenomenal. 2017. Vol 16 hlm 4243 